\title{
Sexualidades no contexto escolar: violência ética e disputas por reconhecimento
}

\author{
Marco Antônio Torres' (D) \\ Izabella Marina Martinho Saraival (D \\ Rubens Modesto Gonzaga' (D)
}

\section{RESUMO}

Este texto apresenta uma pesquisa que investigou a produção da violência ética e do reconhecimento das sexualidades em contextos escolares. Entendemos que a radicalização da teoria do reconhecimento, por Judith Butler, tem possibilitado análises importantes sobre os vínculos entre política e moral. Uma das facetas da violência ética caracteriza-se pela obliteração do relato de si, do silenciamento das lutas e dos sofrimentos de lésbicas, gays, bissexuais, travestis, transexuais, intersexuais e mais (LGBTI+). Para nossas análises, promovemos grupos focais e uma entrevista narrativa com docentes da educação básica de escolas públicas. A pesquisa é fruto do trabalho de um conjunto de pesquisadores/as que nos últimos quatro anos, em um curso de mestrado, se envolveram com o tema das sexualidades nos contextos escolares. Nossas análises apontam tanto para a produção de vidas insuportáveis como para a constituição de resistências que buscam pela possibilidade de vidas habitáveis, porém numa ambiência marcada por discursos contrários às sexualidades.

PALAVRAS-CHAVE

sexualidades; escola; violência ética; reconhecimento; LGBTfobia.

'Universidade Federal de Ouro Preto, Mariana, MG, Brasil. 


\title{
SEXUALITY IN THE SCHOOL CONTEXT: ETHICAL VIOLENCE AND DISPUTES FOR RECOGNITION
}

\begin{abstract}
This paper presents a research that investigated the production of ethical violence and the recognition of sexualities in school contexts. We understand that Judith Butler's radicalization of the theory of recognition has provided important insights on the links between politics and morals. One of the facets of ethical violence is characterized by the obliteration of self-reporting, the silencing of lesbians, gays, bisexuals, transgenders, intersexes, and more (LGBTI+) struggles and sufferings. For our analysis, focus groups and a narrative interview with teachers of basic education of public schools were promoted. The research is the result of the work of a group of researchers who, in the last 4 years, in a master's degree course, have been involved with the theme of sexualities in school contexts. Our analyzes point to both the production of unbearable lives and the constitution of resistances that seek the possibility of livable lives, but in an environment marked by discourses contrary to sexualities.
\end{abstract}

KEYWORDS

sexualities; school; ethical violence; recognizing; LGBTphobia.

\section{SEXUALIDAD EN EL CONTEXTO ESCOLAR: VIOLENCIA ÉTICA Y DISPUTAS POR RECONOCIMIENTO}

\section{RESUMEN}

Este artículo presenta una investigación que investigó la producción de violencia ética y el reconocimiento de las sexualidades en contextos escolares. Entendemos que la radicalización de la teoría del reconocimiento por parte de Judith Butler ha proporcionado importantes conocimientos sobre los vínculos entre política y moral. Una de las facetas de la violencia ética es la eliminación de la autoinforme, el silenciamiento de las luchas y sufrimientos de lesbianas, gais, bisexuales, transgéneros, intersexuales y más (LGBTI+). Para nuestro análisis promovimos grupos focales y una entrevista narrativa con maestros de educación básica de escuelas públicas. La investigación es el resultado del trabajo de un grupo de investigadores que en los últimos 4 años, en un curso de maestría, se han involucrado con el tema de las sexualidades en contextos escolares. Nuestros análisis apuntan tanto a la producción de vidas insoportables como a la constitución de resistencias que buscan la posibilidad de vidas habitables, pero en un ambiente marcado por discursos contrarios a las sexualidades.

PALABRAS CLAVE

sexualidades; escuela; violencia ética; reconocimiento; LGBTfobia. 


\section{INTRODUÇÃO}

O presente artigo apresenta uma pesquisa que investigou a produção da violência ética e do reconhecimento das sexualidades nos contextos escolares. Aqui utilizamos a noção de sexualidades para pensar na afirmação das identidades e das não identidades que se apresentam na contemporaneidade, algo que se aproxima do acrônimo LGBTI+ (lésbicas, gays, bissexuais, travestis, transexuais e intersexuais e o sinal de + indicando uma abertura a outras performatividades de gênero $)^{1}$, sem abrirmos mão dos desdobramentos da sigla no cotidiano escolar e nas políticas públicas. Acreditamos que a noção LGBTfobia é uma derivação do acrônimo, bem como transfobia e lesbofobia, sendo ambas irredutíveis uma à outra e tendo seus usos orientados por estratégias políticas e metodológicas. Ainda assim, ressaltamos que o uso menos rigoroso dessas noções, por nós, indica a necessária atenção a termos êmicos negociados no contexto atual, pois opções teórico-metodológicas podem dizer de posições políticas presentes em nossas vidas. A identidade dos sujeitos como afirmação possível de si, a partir e além dos processos identitários, se torna inteligível com a compreensão do gênero como um ato performático. Esse ato fala do modo como as formas de existência se aproximam da norma de gênero (Butler, 2003).

$\mathrm{O}$ regime de performatividade trazido por Judith Butler refere-se à reiteração da matriz heterossexual e a suas falhas no ato de repetição, o que possibilita outras formas de performatividade (Butler, 2003) que nem sempre desfrutam inteligibilidade moral e política por contestarem e/ou transformarem a norma, ainda que isso não se faça livre das amarras normativas do gênero e das sexualidades (Butler, 2015). Butler elaborou essa análise utilizando de maneira intensa a obra de Michel Foucault. Assim, ela entende que a adesão ou contestação de uma performatividade heterossexual pelos sujeitos sempre ocorrerá em dado regime de verdade, este considerado haja vista a obra foucaultiana (Foucault, 2018a). Logo, as siglas e suas transformações são marcadores históricos que indicam os processos de produção de diferenças e diferenciações da des/articulação de sujeitos políticos (Brah, 2006). Pelo ato de nomeação que fazem na arena pública, siglas como LGBTI+ têm conseguido, muitas vezes, produzir inteligibilidade política na cena pública, bem como formas de reconhecimento.

As noções de violência ética e de reconhecimento foram escolhidas por levarmos em conta que elas possuem grande potência na análise de disputas morais e políticas, como julgamos ser a questão das sexualidades nos contextos escolares. Butler (2015) analisa as noções de violência ética, reconhecimento e esperança para pensar os limites/as possibilidades do sujeito em relatar a si mesmo diante das interpelações que sofre. Tal reconhecimento pode acontecer em três momentos, que se entrecruzam: diante do coletivo, diante do outro e diante de si mesmo. Moral e política constituem ambiência para a produção do silenciamento ou reconhecimen-

1 O uso do acrônimo LGBTI+ foi escolhido seguindo a orientação do Manual de Comunicação LGBTI+, produzido pela Aliança Nacional LGBTI e GayLatino, entidades que possuem articulações importantes com o movimento LGBTI+ em nosso contexto de pesquisa (Reis, 2018). 
to de LGBTI+, tendo entre uns e outros zonas cinzentas que dizem de ruídos ou indícios de vozes possíveis.

Uma das facetas da violência ética caracteriza-se pela obliteração do relato de si, da emergência do reconhecimento daqueles/as que sofrem interpelações e ataques com base em sua contestação da norma de gênero, ou seja, no dimorfismo sexual, no privilégio do homem e na heterossexualidade compulsória (Butler, 2003). Essa violência surge sempre que um jovem gay é impedido de narrar seu sofrimento, seja na sua escola, seja em outro lugar. O impedimento dá-se pelo desprezo do coletivo, pelas ameaças do outro, pelas coações emocionais do sujeito ou por tantos modos em que a mudez fabrica silêncios e medo. Portanto, temos a violência ética operando em favor da LGBTfobia. Esta pode ser compreendida como um dispositivo (Foucault, 1988) de regulação dos corpos de LGBTI+, entre outras formas de existência que desafiam a norma de gênero por práticas discursivas ou não discursivas.

Ainda que certa polêmica exista acerca das noções como homofobia, lesbofobia e seus similares (Costa e Nardi, 2015; Junqueira, 2007), como a junção LGBTfobia, elas adentram cada vez mais como conceitos e/ou categorias analíticas na produção acadêmica (Borrillo, 2010), nos textos das políticas públicas e nos instrumentos de direitos humanos (Brasil, 2009). Esses termos provêm da pauta do ativismo social e dão inteligibilidade à experiência das sexualidades. A tensão, não rara, entre posições acadêmicas, políticas públicas e movimentos sociais, no contexto de gênero e sexualidades, não deveria bloquear alianças necessárias para o avanço de pautas políticas, pois poderia produzir o epistemicídio de importantes elementos na articulação de direitos de LGBTI+.

Aqui trazemos a noção de epistemicídio articulada por Sueli Carneiro (2005) na análise das dominações raciais com base nas leituras que ela fez de outros autores. Para a teórica, essa noção "tem se constituído no instrumento operacional para a consolidação das hierarquias raciais por ele produzidas, para as quais a educação tem dado contribuição inestimável” (Carneiro, 2005, p. 33), sendo capaz de apagar saberes e fazeres no contexto em que se articula. Acreditamos que negar e/ou desacreditar termos êmicos ou categorias ainda frágeis das lutas sociais LGBTI+ é operar de modo epistemicida, pois mata em broto saberes e fazeres irrenunciáveis para a produção de uma frondosa democracia participativa nos contextos sociais, algo que desejamos a todas as escolas. Numa perspectiva dos debates sobre educação, democracia e justiça, temos autores que apontam cenários para essa ambiência política. $\mathrm{Na}$ ótica de uma justiça curricular, o pesquisador espanhol Jurjo Torres Santomé (2013, p. 163) considera ser "preciso aceitar a pretensão de que o século XXI deve ser o século da justiça social, da paz, da compreensão e da solidariedade global e trabalhar para isso". Assim, as escolhas metodológicas também dizem das orientações políticas de uma pesquisa.

Também, entendemos, fundamentados em Wladimir Saflate (2015), que a radicalização da teoria do reconhecimento, por Butler, tem possibilitado análises importantes sobre os vínculos entre política e moral. Recortamos em nossa pesquisa relatos que falam daqueles/as que têm sido des/classificados/as nas escolas 
haja vista formas de existência além da cisheteronormatividade. A noção de cisgeneridade foi proposta por ativistas transfeministas "como um neologismo no sentido de atribuir um nome às matrizes normativas e ideais regulatórios relativos às designações compulsórias das identidades de gênero" (Mattos e Cidade, 2016, p. 133). Portanto, essa noção tem sido capaz de produzir diferenciações de pessoas auto ou heteroclassificadas como travestis, transexuais, transgêneros etc. A noção de cisheteronormatividade articula-se como "uma perspectiva que tem a matriz heterossexual como base das relações de parentesco e a matriz cisgênera como organizadora das designações compulsórias e experiências das identidades de gênero" (Mattos e Cidade, 2016, p. 134).

Consideramos que é relevante o uso dessas noções por proporcionarem análises que se aproximam de uma semântica das lutas de LGBTI+ e de suas experiências. "O saber da experiência é aquele que se adquire no modo como alguém vai respondendo ao que lhe vai acontecendo, ao longo da vida e no modo como vamos dando sentido ao acontecer do que nos acontece" (Bondía, 2015, p. 32). A voz do $e u$ da experiência pode emergir dos relatos de docentes, das lutas de movimentos sociais e muitas vezes, de forma inusitada, do silêncio diante da violenta inquirição normalizadora. Desse modo, "não se trata apenas de a ética se encontrar envolvida na tarefa da teoria social, mas a teoria social, se tiver que produzir resultados não violentos, deve encontrar um lugar de vida para esse 'eu"' (Butler, 2015, p. 19).

Nossa perspectiva teórico-metodológica escolheu a construção de dados com base na voz de docentes da educação básica pública, pois ela também produz as análises levando em conta termos que se sustentam por semânticas produzidas pela voz dos sujeitos da experiência. A voz desses docentes permite analisar saberes e fazeres que ocorrem no cotidiano escolar, a partir e além do currículo oficial, apontando-nos a qualidade das relações humanas que ali são engendradas, conforme nos indica Torres Santomé (2013). Este compreende que nossa época vive um conjunto de 12 revoluções em diferentes domínios da existência, como comunicação, ecologia, lazer, entre outros, com destaque às revoluções na educação. Nesta podemos identificar a emergência de grupos que historicamente sofreram exclusão imposta, como mulheres, negros/as, LGBTI+, entre outros. Tais grupos produzem resistência por meio das lutas de coletivos, de movimentos sociais, entre outros tipos de ativismo. Também, revolucionam os domínios educacionais pautando desde as práticas pedagógicas até os conteúdos dos livros didáticos, alcançando práticas além do currículo oficial.

$\mathrm{O}$ que essas/es docentes escutam e/ou como se posicionam diante daquilo que se produz na escola acerca das sexualidades? Como dialogam com as revoluções da educação conforme apontado anteriormente? Para responder a essas questões, além do diálogo teórico, temos produzido análises empíricas. Os autores deste artigo possuem diferentes contatos com a escola: uma pedagoga/pesquisadora da educação infantil e ensino fundamental, um professor de cursos profissionalizantes/pesquisador e um professor universitário pesquisador, todos envolvidos com o projeto de pesquisa que deu origem ao presente texto. A pesquisa foi desenvolvida 
em duas cidades de médio porte ${ }^{2}$, num raio de $100 \mathrm{~km}$ aproximadamente de Belo Horizonte (MG). Ainda assim, omitimos os nomes dos municípios considerando que sua menção poderia quebrar o anonimato da entrevista narrativa.

Nossa pesquisa situa-se num prisma que dialoga com os debates sobre gênero e sexualidades numa visão pós-estruturalista, politicamente posicionada no desenho metodológico que se propõe a seguir. Essa posição pode ser percebida no reconhecimento da legitimidade das formas de existência que vão além e permanecem distantes daquelas reguladas pela cisheteronormatividade. Oliveira e Ferrari (2018) descreveram esse contexto de produção acadêmica como uma perspectiva das teorias pós-críticas, dispostas a enfrentar os desafios que permeiam as lógicas da heteronormatividade, tão presentes nas escolas. Para os autores, investigar os desdobramentos das questões de gênero e das sexualidades na escola possibilita entender o sistema educacional por dentro, ou seja, problematizar a construção social e histórica dos sujeitos. Ainda mais, ao colocar em análise esses processos, construímos e desconstruímos relações de poder com os outros, isto é, no campo de pesquisa, em que encontramos pesquisadores/as, colaboradores/as, gestores/as públicos etc. Isso também se relaciona às práticas docentes que adotamos nas escolas e em salas de aula, possibilitando visibilidades da potencialidade de sujeitos muitas vezes negligenciados no contexto escolar (Torres Santomé, 2013).

Nosso trabalho seguiu as orientações e os trâmites solicitados pelo comitê de ética em pesquisa envolvendo seres humanos, sendo utilizados pseudônimos para todos/as os/ as colaboradores/as da pesquisa. Escolhemos os relatos de docentes por considerarmos a importância dessa perspectiva de observação no contexto escolar. Apesar de o presente texto manter o nome de dois pesquisadores e uma pesquisadora, a investigação é fruto de um conjunto de pesquisadores/as que nos últimos anos, em um curso de mestrado, se envolveram com o tema das sexualidades nos contextos escolares. Os grupos focais foram conduzidos pela pedagoga, também autora deste artigo, entre maio e outubro de 2018. A entrevista narrativa foi realizada pelo professor do curso profissionalizante, outro autor deste artigo, no ano de 2017. Todos os procedimentos de pesquisa ocorreram depois de terem sido analisados e discutidos pela equipe de pesquisa.

Nos relatos dos/as docentes, destacamos como eles/as percebem as sexualidades, pois isso diz das possibilidades de se nomear/denunciar a LGBTfobia. No cotidiano escolar pode se construir uma ciência racista, sexista, classista e homofóbica, produzindo "a deformação, o silenciamento e a manipulação de determinados dados e situações" (Torres Santomé, 2013, p. 284). Isso dá-se diante da emergência de proposições de políticas públicas articuladas às questões de gênero e sexualidades, como o Plano Nacional de Promoção da Cidadania e dos Direitos Humanos de LGBT (Brasil, 2009) e seus desdobramentos na administração pública (Vianna, 2018). Problematizamos tal questão, pois consideramos que a violência ética tem

2 Segundo o Instituto Brasileiro de Geografia e Estatística (Brasil, 2011), cidades de pequeno porte são aquelas com até 50 mil habitantes, e de médio porte, aquelas até 100 mil. As cidades da presente pesquisa têm entre 50 e 100 mil habitantes, porém podem ser consideradas de médio porte por apresentarem crescimento significativo de suas populações nos últimos anos. 
produzido formas de existência insuportáveis de se viver, impedindo processos de reconhecimento em diferentes espaços sociais. Dessa insuportabilidade da existência, os sujeitos movem-se de muitas maneiras. "Tem gente que chega pra ficar. Tem gente que vai pra nunca mais. Tem gente que vem e quer voltar. Tem gente que vai e quer ficar. Tem gente que veio só olhar. Tem gente a sorrir e a chorar" (Nascimento e Brant, 1985). A letra dos compositores mineiros ajuda a entender que a saída de uma vida insuportável nem sempre é o fim. Os deslocamentos que ela provoca pode gerar ações, lutas e, entre outras questões, o luto por quem decidiu partir.

\section{VIOLÊNCIA ÉTICA NOS ESPAÇOS ESCOLARES: A PROMOÇÃO DO DISCURSO REACIONÁRIO RAIVOSO CONTRA AS SEXUALIDADES}

A possibilidade de lidar com as formas de existência humana, seja da nossa, seja de outrem, está relacionada com as possibilidades que temos de relatá-las ou de exercitar seu reconhecimento. Assim, podemos criar nossos mundos e compartilhá-los nas trajetórias de nossas experiências. O contexto escolar é um dos lugares importantes em que nossas experiências ganham sentido, pois, para uma parte significativa de crianças, adolescentes e adultos, esse lugar pode ser uma ambiência em que é possível experimentar-se. Além disso, a escola já não se limita mais por seus muros, nem está orientada apenas pelas políticas públicas nem por sua gestão, pelas formas de contestação, transformação e defesa das normas de um regime de verdade. Este é utilizado com base nas últimas elaborações de Foucault (2018a) para analisar as performatividades de sexo e gênero (Butler, 2003) nas interdependências sociais da escola. Nestas devemos considerar, conforme aponta Torres Santomé (2013), que a análise do currículo deve levar à justiça curricular, ou seja, a efetivar o reconhecimento das demandas das salas de aula, das necessidades de todos os grupos sociais, principalmente daqueles que apresentam maiores urgências. Essa ambiência democrática pode propiciar a produção de relações marcadas pela ética, pela solidariedade e pela colaboração na formação de todos/as diante do avanço das políticas neoliberais que têm atacado nossas democracias.

Kátia Baggio (2016) produz uma análise que nos ajuda a pensar a articulação de posições consideradas de ultradireita no cenário internacional. Ela analisa articulações entre certos think-tanks brasileiros com organizações internacionais desde os anos de 1980, para a promoção de uma agenda da direita ultraliberal. Baggio produziu dados que nos auxiliaram a percebem como a organização ultraliberal Atlas Network, fundada na década de 1980, construiu articulações no Brasil com grupos como o Instituto Millenium (IMILL) e com o Estudantes Pela Liberdade (EPL), ambos provavelmente apoiadores do Escola Sem Partido, algo que ainda investigamos em outra pesquisa. Isso ajuda-nos a descrever as interdependências sociais atuais. Com isso, passamos a compreender que plataformas como Facebook, WhatsApp etc. fazem parte do cotidiano escolar, bem como carreiam para os pátios e salas da aula, em frações de segundos, disputas de todas as ordens, mesmo aquelas relacionadas à ofensiva antigênero (Prado e Correa, 2018). Nessa ofensiva, emerge com destaque na opinião pública e nas políticas públicas em educação o sintagma 
ideologia de gênero (Junqueira, 2018), buscando sustentar posicionamentos que "têm sido utilizados para rotular práticas educativas que problematizem opressões e desigualdades sociais" (Mattos, 2018, p. 573). O mapeamento dessa ofensiva revela seu recrudescimento na última década.

Nesse mesmo ano (2013) então, no Brasil, forças católicas e evangélicas conservadoras e o movimento Escola sem Partido juntaram esforços para incidir, de forma coordenada, nos debates do Plano Nacional de Educação com o objetivo de excluir o termo gênero dos documentos em debate. Em 2016, o ataque ao gênero, como ideologia "diabólica e marxista" impactou, negativamente, no referendo sobre o acordo de Paz na Colômbia. Um ano mais tarde, a filósofa feminista Judith Butler, ao visitar o Brasil, foi objeto de um virulento ataque antigênero. No começo de 2018, a mesma diatribe levou um candidato, representando a cruzada antigênero, ao segundo turno das eleições presidenciais. Alguns meses depois, o tropo "gênero" esteve no vórtex central do furacão eleitoral brasileiro e, no país, o ano de 2019 , se iniciou com o anúncio feito no discurso presidencial ao congresso de que um dos objetivos do governo recém eleito é combater a "ideologia de gênero". (Prado e Correa, 2018, p. 444)

Nesse contexto, localizamos a produção de um currículo fechado, em que as lógicas das políticas neoliberais, numa perspectiva economicista orientada pelo capitalismo hegemônico (Torres Santomé, 2013), se articulam aos regimes de verdade e operam na escola. Os regimes de verdade podem dar andamento a relações de poder nas instituições disciplinares por um conjunto ordenado de elementos capazes de controlar discursos em vistas de uma verdade (Foucault, 2018a). O discurso constitui-se em um conjunto de enunciados capazes de "atravessar" a linguagem, conforme analisa Fischer (2001). Desse modo, podemos compreender o enunciado da ofensiva antigênero de que a "ideologia de gênero' é diabólica e marxista", conforme citado por Prado e Correa (2018, p. 444). O exercício do poder como uma rede de relações entre sujeitos é "o que se poderia chamar de tecnologia política do corpo que nada mais é do que uma microfísica do poder posta em jogo pelos aparelhos e instituições" (Foucault, 1987, p. 29).

Destacamos que Michel Foucault, entre o fim da década de 1970 até seu falecimento, em 1984, trabalhou a noção de governo para pensar as formas de regulação da vida, sendo importante observar o seguinte. Aqui buscamos operar com a noção de discurso na mudança que o filósofo propõe do uso da noção de poder para governo, em que a produção da verdade terá grande relevância analítica para discutir regimes de verdade. Todavia, cabe ressalvar como ele definiu essa noção em 1980:

Nos cursos dos dois últimos anos, procurei esboçar um pouco essa noção de governo, que me parece muito mais operacional do que a noção de poder, "governo" entendido, claro, não no sentido estrito e atual de instância suprema das decisões executivas e administrativas nos sistemas estatais, mas no sentido lato, e aliás antigo, de mecanismos e procedimentos destinados a conduzir os homens, a dirigir a conduta dos homens, a conduzir a conduta dos homens. (Foucault, 2018a, p. 13) 
Um bom exemplo disso é como as noções de gênero e diversidade sexual passaram de conceitos analisadores/mobilizadores das relações de poder na escola para termos malditos, banidos da inteligibilidade em muitos planos de educação em estados e municípios e na esfera nacional. Consideramos que nessa mudança operam a deformação e o silenciamento (Torres Santomé, 2013) daquilo que se define como direitos de mulheres e LGBTI+ pela ação da ofensiva antigênero. A deformação dá-se ao acusar o reconhecimento desses direitos na escola como ideologia de gênero, ao mesmo tempo em que se pretende silenciar as vozes daqueles/as que no cotidiano escolar estariam defendendo tais direitos. Essas relações poderiam ser compreendidas como a produção de formas de governabilidade dos corpos, ou seja, formas de conduzir os sujeitos por verdades estabelecidas pelas lógicas cisheteronormativas. Deve-se atentar ao fato de que a emergência do debate de gênero e das sexualidades na educação sempre foi complicada, mas nas agendas dos governos Fernando Henrique Cardoso e Luiz Inácio Lula da Silva ocorreram articulações importantes (Vianna, 2018), como veremos mais adiante. Isso serviria para pensar o que tem acontecido também com outras minorias sociais. Destacamos que essas disputas vão além de lógicas nacionais e contextos específicos, como as escolas.

Nos últimos anos, estudiosos e estudiosas de diversas partes do mundo têm observado uma marcante e incisiva presença de um ativismo religioso - não raro, acompanhado por grupos laicos ou não nitidamente confessionais — que encontraram em um neologismo ou, mais precisamente, no sintagma neológico "ideologia de gênero" (ou "teoria do gênero" e outras variações), um artefato retórico e persuasivo em torno do qual reorganizar seu discurso e desencadear novas estratégias de mobilização política e intervenção na arena pública. (Junqueira, 2018, p. 451)

Entendemos que a LGBTfobia, nessa dinâmica social, opera a produção de vidas insuportáveis, ou seja, formas de vida que têm negada ou questionada sua inteligibilidade. Essas existências podem se tornar insuportáveis à medida que se afastam da cisheteronormatividade, que "medicaliza e criminaliza subjetividades que não se enquadram nessas normas" (Mattos e Cidade, 2016, p. 141). Pela cisheteronormatividade, põem-se em funcionamento dispositivos dinâmicos que buscam eliminar e/ou subalternizar determinadas formas de existência. Esses dispositivos têm sido nomeados como lesbofobia, homofobia, bifobia, transfobia ou mesmo pelo neologismo LGBTfobia. Fazemos o uso desses termos, em nossas pesquisas, de acordo com o contexto das análises. Observamos que as sexualidades e as questões de gênero se constituem como outros marcadores sociais da diferença, como raça, classe social, entre outros. Esses marcadores entrecruzam os campos político e acadêmico por um aporte feminista e antirracista (Moutinho, 2014; Oliveira e Ferrari, 2018). Um exemplo disso, verificado pela pedagoga/pesquisadora no contexto escolar no qual trabalha, é como meninas negras são inferiorizadas e excluídas nos momentos de participação coletiva. 
Raça, sexualidade e gênero, por exemplo, são três marcadores que se tornaram alvo de ataques nos contextos das conferências (municipais, estaduais e nacional) de educação, sendo algumas das categorias que foram banidas ou esgarçadas nos documentos finais do Plano Nacional de Educação. Essa análise das mudanças de noções mobilizadoras para termos malditos não é completa, mas ainda assim diz de um contexto de influência muito específico no Brasil. A análise da recolonização da esfera civil pelo discurso religioso tem contribuído para essa mudança.

Percebe-se que se formou uma aliança composta por evangélicos e católicos mais ortodoxos, quando não fundamentalistas, bem como organizações conservadoras/ reacionárias que defendem o que chamam de família e costumes tradicionais, unidas em divulgar e disseminar informações distorcidas para impedir que se alcance a equidade entre os gêneros e o respeito à diversidade sexual, conforme vem sendo ratificado internacional e nacionalmente há décadas com a intenção de diminuir as discriminações e as violências baseadas em gênero. (Reis e Eggert, 2017, p. 18)

A propagação de discursos promotores do medo e do ódio ganha espaço quando consegue grande penetração social por meio das mídias sociais, principalmente quando gestores/as públicos se assumem, nesses contextos, favoráveis ao que o texto citado define como organizações conservadoras/reacionárias. Podemos observar essas questões nos grupos focais que aconteceram no ano de 2018, numa cidade de médio porte próxima a Belo Horizonte. Ao todos, foram três grupos focais, dos quais todos/as os/as colaboradores/as participaram voluntariamente. O primeiro ocorreu no modelo de oficina como preparação para os demais. A oficina de grupo focal foi composta de professores/as que cursam o mestrado do programa em que a pesquisa foi desenvolvida, nas dependências da universidade, contando com quatro participantes, e durou pouco mais de 60 minutos. Os outros dois grupos ocorreram após avaliação da oficina pela equipe de pesquisa. Um deles foi realizado numa escola municipal com sete participantes e duração de aproximadamente 80 minutos; o outro foi numa escola municipal com a participação de cinco pessoas e levou por volta de 70 minutos. Já com áudio e filmagem ligados, apresentados/as o/a observador/a e os/as operadores/as de áudio e vídeo, foi reiterado a todos/as o tema da pesquisa, apresentando aos/às colaboradores/as por escrito um roteiro para o grupo, após a leitura e assinatura do Termo de Consentimento Livre e Esclarecido e do Instrumento de Cessão de Direitos. A depender do andamento do grupo, a mediadora propunha ou não mais questões. Os/as colaboradores/as tiveram formas de participação bem diferentes, porém houve grande colaboração de todos.

Pelos grupos focais, percebemos troca de opiniões, de valores, de crenças, de experiências. No grupo focal, as interações provocam análises e afetações, criando uma ambiência para autorreflexões, como apontam discussões dessa metodologia (Barbour, 2009; Gatti, 2005; Smeha, 2009). Algumas falas num grupo focal indicam como professoras/es, num processo de reflexividade, conseguem notar a cisheteronormatividade no exercício da docência, ainda que a nomeiem de outro modo. Aqueles fatos que seriam tratados no cotidiano escolar como sem importância ganham significado. 
A gente entra na faculdade, participa desses debates sobre gênero, o que é ser mulher, o que é ser homem. E diz que nunca vai fazer isso como professor, né, jamais eu vou fazer isso. E para minha surpresa e durante essa conversa que eu pensei nisso [...]. E teve um dia inclusive que nós começamos com essa conversa na sala. E teve um menino que falou assim: "Mas eu procuro fazer minha letra bonita mesmo, porque a letra quando é bonita a professora dá nota boa. Porque as meninas têm tudo nota boa". (Grupo Focal, professor Gilberto Freyre $^{3}$, 2017)

O professor Gilberto Freyre indica como a fala do aluno produz uma reflexividade que leva o docente a perceber as expectativas de gênero nos processos avaliativos. Em sua observação, há a contestação de um padrão consensual de comportamento feminino/masculino que já está naturalizado em nossas ações, sem que nos demos conta disso. Isso aponta para uma posição crítica do professor em relação a uma governabilidade sexista sobre o modo de escrever. Outra fala também analisa o poder da naturalização das questões de gênero e das sexualidades no nosso cotidiano:

Isso está enraizado na gente mesmo, por mais liberal que a gente seja, ou a gente acha que a gente é. Mas a gente falando a gente reflete, mas você não está errado. Não quer dizer que você esteja errado de ser assim. É porque a gente tem isso tudo enraizado dentro da gente. Eu mesma se for começar aqui a analisar coisas que eu fiz ou que eu faço em relação a minha vida diante de outras pessoas ou o meu posicionamento diante de outras pessoas, eu vou encontrar um monte de coisa que pode ser considerada defeito, pode ser considerada uma coisa errada. (Grupo Focal, Professora Marie Curie, 2018)

Não obstante, encontramos relatos de aulas de educação física em que ficava explícita a generificação dos corpos. Esta diz de um modo de distribuição e organização dos corpos por uma governabilidade que impede às mulheres de acessarem os mesmos lugares que os homens nos domínios da escola. Dois dos grupos são enfáticos ao relatar como há separação entre as atividades destinadas aos meninos e às meninas, de como as meninas enfrentam dificuldades em serem aceitas e participar dos times de futebol masculinos:

Eu trabalhei em uma escola que tinha uma menina que ela detestava fazer qualquer coisa na educação física que não fosse jogar futebol, e ela jogava futebol muito melhor que qualquer um dos colegas dela. E ela era vetada pelo professor de educação física o tempo todo, porque a diretora achava que aquilo estava errado. E ela não podia participar do jogo de futebol porque aquilo era só para menino. E ela participava de um time de futebol feminino

3 Todos os nomes são pseudônimos e foram escolhidos com base em pesquisadores/as, autores/as, educadores/as de relevância na área da educação ou ainda de autodenominações dos/as colaboradores/a. 
fora da escola. E quando tinha campeonato de futebol feminino ela também participava. Mas aconteceu, por exemplo, de no campeonato masculino faltar um aluno que era importante durante jogo. E essa menina estava lá disponível, queria participar, os meninos queriam que ela participasse e ela foi vetada. Com muito custo, ela conseguir participar e ganhou o jogo. (Grupo Focal, Professora Marie Curie, 2018)

Outra participante disse que trabalhou em uma escola onde os meninos faziam uso da quadra e aprendiam as modalidades esportivas, enquanto às meninas era destinado um pequeno espaço do pátio que mal dava para rebater uma peteca. Não é norma que meninas participem de atividades vistas como masculinas. No futebol, por exemplo, não cabem mulheres, principalmente se elas denunciam a não naturalidade da norma com o seu talento e capacidade. A educação física surge como um local em que meninos e meninas recebem tratamento diferenciado. Essa separação dos corpos é uma forma de perpetuar padrões de comportamentos dicotômicos. "Essa luta com as condições não escolhidas da vida — uma ação também é possível, paradoxalmente, graças à persistência dessa condição primária de falta de liberdade" (Butler, 2015, p. 31).

Também destacamos dois relatos que indicam como a homofobia se põe em defesa de um regime de verdade, orientado pela cisheteronormatividade, que persiste no cotidiano escolar:

No $6^{\circ}$ ano, dos mais novinhos, eu estava estudando um texto lá com eles, o depoimento da mãe, mãe de uma jovem homossexual, e aí, no meio do debate, um menino virou e falou assim: "É... Fulano, você pode preparar que você está na mira do Bolsonaro". Eu falei: "Gente, não vamos colocar política aqui no meio, não, gente". "Bolsonaro vai matar todos os viados". (Grupo Focal, Professor Moreno, 2018)

"No 7o ano falando de política, de Bolsonaro: 'cuidado, viu, fulano, cuidado" (Grupo Focal, Professora Helô, 2018).

No contexto da interpelação que sofre esse menino pode emergir (nele, no outro e/ou na coletividade) a reflexividade. Tornar-se alvo da homofobia, no caso desse aluno, não é uma condição, mas uma contingência. Ou seja, "o sujeito luta invariavelmente com condições de vida que não poderia ter escolhido" (Butler, 2015, p. 31). Temos a constituição de uma violência ética quando a comunidade escolar não propicia o relato de si no cenário dessa ameaça. Isso impede possibilidades do reconhecimento, de fornecer ao sujeito oportunidades de um registro inteligível de sua existência nas interdependências sociais. Vejamos um pouco mais das relações entre moral e política no contexto da violência ética.

Butler (2015), com base em Theodor Adorno, considera que, quando o "ethos coletivo" deixa de ser compartilhado por todos/as, ele passa a utilizar métodos violentos para impor-se como comunidade. A autora, nessa mesma perspectiva, entende que, no momento em que as formas de existência não cabem mais nas máximas morais derivadas desse ethos, essa máxima se torna um anacronismo. 
O grande problema surge quando pensamos em termos históricos, no momento em que esse ethos anacrônico não se torna pretérito. Ao permanecer como anacronismo, ele esgarça o presente, não consegue dar inteligibilidade às formas de existência que revelam a possibilidade de universais abertos a diferenças. $\mathrm{O}$ anacronismo que não se torna passado aparece quando alguém é ameaçado haja vista sua sexualidade: "Você está na mira do Bolsonaro" e "Bolsonaro vai matar todos os viados". Portanto, "cuidado, viu, fulano, cuidado". As falas podem emergir como enunciados, no sentido foucaultiano; a produção de significados apoia-se em sistemas discursivos (Fischer, 2001) morais, religiosos, pedagógicos, entre outros. "O que permitirá situar um emaranhado de enunciados numa certa organização é justamente o fato de eles pertencerem a uma certa formação discursiva” (Fischer, 2001, p. 202). Determinado enunciado pode se constituir de diferentes modos, até de uma posição discursiva do sujeito reflexivo, mas disso não devemos supor a norma como produtora do sujeito em si, ou mesmo que o sujeito seja plenamente livre para desprezar a norma que instaura sua reflexividade (Butler, 2015). Todavia, reiteramos, Butler (2015) vê que a opacidade do sujeito sempre permeia todos os momentos do reconhecimento, pois o sujeito nunca será totalmente transparente a si mesmo:

Se o sujeito é opaco para si mesmo, ele não totalmente translúcido e conhecível para si mesmo, ele não está autorizado a fazer o que quer ou a ignorar suas obrigações com os outros, decerto o contrário também é verdade. A opacidade do sujeito pode ser uma consequência do fato de se conceber como ser relacional, cujas relações primeiras e primárias nem sempre podem ser apreendidas pelo conhecimento consciente [...]. Então essa opacidade parece estar embutida na nossa formação e é consequência de nossa condição de seres formados em relações de dependência. (Butler, 2015, p. 32)

Enunciados LGBT fóbicos, como apresentados anteriormente, emergem de formações discursivas que operavam durante a campanha do então candidato Jair Messias Bolsonaro, que venceu as eleições presidenciais no Brasil em 2018. Eles dizem da produção de um regime de verdade que busca nomear atos de violência, injúria e ameaça como liberdade de expressão, defesa da família, opção religiosa etc.

E tudo está imerso em relações de poder e saber, que se implicam mutuamente, ou seja, enunciados e visibilidades, textos e instituições, falar e ver constituem práticas sociais por definição permanentemente presas, amarradas às relações de poder, que as supõem e as atualizam. (Fischer, 2001, p. 200)

Esse menino classificado como viado pelo enunciado "Bolsonaro vai matar todos os viados" pode experimentar uma vida insuportável. Dessa insuportabilidade, ele tentará escapar. Nesse momento, quando a possibilidade do armário se tornar insuficiente, qual será sua destinação? Será ele "gente que chega pra ficar" ou "gente que vai pra nunca mais"? A questão do suicídio e/ou sua ideação suicida tem aparecido mais como discussões nas redes do que em pesquisas acadêmicas. Em nossas análises, a temática do suicídio de LGBT+ (ou suas ideações) tem 
sido recorrente em anais de congressos e publicações livres, porém ainda temos poucos artigos acadêmicos nacionais discutindo a questão. Das pesquisas encontradas, destacamos uma realizada com adolescentes não heterossexuais, entre $12 \mathrm{e}$ 20 anos, que aponta para a necessidade de abordagens específicas para esse grupo (Teixeira-Filho e Rondini, 2012).

Assim, temos a emergência de uma das facetas da violência ética. Ela se constitui quando as vozes desses sujeitos são caladas e/ou desqualificadas, o que acontece por meio de discursos que historicamente definiram a diferença como uma anormalidade a ser corrigida pela medicalização ou disciplina, muitas vezes às custas de muito sofrimento e à revelia do sujeito. $\mathrm{O}$ silenciamento dessas vozes opera em desfavor da potência enquanto estudantes, docentes, participantes de uma comunidade escolar. Consideramos que a voz é uma metáfora para dizer daquilo que a experiência nos informa, mesmo no caso daqueles que não falam por diferentes motivos. Entre eles, "tem gente que vai pra nunca mais", pelo suicídio, pelo assassinato de mulheres, gays, lésbicas e principalmente pelo extermínio de travestis e transexuais em nosso país. A voz do eu da experiência pode emergir das narrativas de familiares, das lutas de movimentos sociais e muitas vezes, de forma inusitada, do silêncio de alguém que se cala diante da inquirição violenta da normalização. Logo, "não se trata apenas de a ética se encontrar envolvida na tarefa da teoria social, mas a teoria social, se tiver que produzir resultados não violentos, deve encontrar um lugar de vida para esse 'eu"' (Butler, 2015, p. 19). Desse modo, as investigações precisam pensar em sua própria limitação em dizer desses sujeitos, exigindo de nós, pesquisadores/as, aproximações que reconheçam as vozes daqueles/ as que relatam acerca de si.

\section{RECONHECIMENTO DAS SEXUALIDADES NOS ESPAÇOS ESCOLARES: OU SOBRE “GENTE QUE CHEGA PRA FICAR", "GENTE A SORRIR E A CHORAR"}

Butler (2015), ao analisar os sujeitos foucaultianos, concorda que a cena do reconhecimento se dá num regime de verdade que diz sobre as formas reconhecíveis ou não reconhecíveis, porém numa dinâmica em que contestação e a transformação podem surgir.

Isso não significa que dado regime de verdade estabeleça um quadro invariável para o reconhecimento; significa apenas que é em relação a esse quadro que o reconhecimento acontece, ou que as normas que governam o reconhecimento são contestadas e transformadas. (Butler, 2015, p. 35)

A produção e proliferação de confissões acerca do gênero e das sexualidades alastraram-se por todos os recantos da vida contemporânea, produzindo formas de contestação e transformação que chegaram às salas de aula. Essa capacidade rizomática de produção das sexualidades promove contestações e transformações do regime de verdade, seja os regimes que produziram corpos devassos e pecadores, seja aqueles que produziram e ainda produzem, em certa medida, tais corpos 
como doentes, como anormais. Quando Foucault (1988) analisou a passagem da perspectiva confessional religiosa para aquela de uma scientia sexualis, ainda era difícil imaginar como outras formas de confissão seriam potencializadas pelas redes digitais e outras mídias.

Como pesquisadores/as no campo da educação, problematizamos esses espaços de sociabilidade como educativos, uma vez que modificam nossa forma de ver, ser visto e, principalmente, nossa forma de agir, além de interferir, diretamente, no cotidiano escolar, nos processos de ensino-aprendizagem e nas relações entre professoras/es e alunas/os. [...] Somos, de muitas formas, convocados/as a usar a internet nos seus mais variados fins, de modo que ela alterou, de forma decisiva, as maneiras como pagamos nossas contas, aprendemos e ensinamos, namoramos, nos locomovemos e, principalmente, nos comunicamos e nos mobilizamos. (Oliveira, Ferrari e Machado, 2019, p. 661)

$\mathrm{Na}$ contemporaneidade, é curioso perceber como essas confissões têm sido capazes de produzir contestações nos regimes de verdade sustentados pelos discursos. $\mathrm{O}$ aparecimento dessas contestações — ligeiras, potentes e efêmeras pode ocorrer de muitos modos, penetrando pelas ondas da internet nos lugares mais inusitados. O sintagma ideologia de gênero é um bom exemplo disso, tanto em sua articulação internacional (Junqueira, 2018; Prado e Correa, 2018) como na maneira como adentrou nos discursos das políticas públicas de educação no Brasil (Mattos, 2018).

A comunicação eletrônica em suas diversas modalidades tem sido um veículo poderoso para que os discursos religiosos se articulem ao contexto educacional de forma significativa, na produção de violências LGBTfóbicas. Mesmo que deparemos com o crescimento da notificação de violências de todas as ordens contra os sujeitos identificados pelas sexualidades e contra as mulheres, nem todos/ as sofrem e/ou morrem calados/as. Emergem relatos de vida que frequentam das páginas da internet às metodologias de pesquisa, das lutas sociais aos espaços de gestão pública etc. Assim, temos a produção de formas de reconhecimento das performatividades como contestação da cisheteronormatividade na sociedade. Os discursos que produzem os sujeitos que frequentam as escolas - docentes, estudantes ou membros do corpo técnico - relatam experiências de performatividade que forçam os estreitos limites de um ethos anacrônico que recusa tornar-se passado. $\mathrm{O}$ relato das experiências traz palavras com a potência de produzir reconhecimento, por isso a produção de um discurso reacionário raivoso contra a possibilidade de determinadas palavras como gênero, LGBT e homofobia no último Plano Nacional de Educação.

Podemos trazer um pouco das contestações e transformações do regime de verdade naquilo que nomeiam nossos/as colaboradores/as da pesquisa. Os três grupos focais possibilitaram bons diálogos que provavelmente não iriam emergir em entrevistas individuais. Vejamos como essas questões aparecem nos grupos focais e indicam que existe um processo de reflexividade acerca do gênero e das sexualidades em curso nesses/as professores/as: 
Eu tenho percebido é que existe hoje uma dificuldade grande da escola [de] trabalhar essas questões da sexualidade e gênero, e quando a gente toca nesse assunto a resposta é "os pais não gostam". Parece uma desculpa, "não vamos falar disso, porque os pais não gostam”. Eu não sei se isso é uma realidade ou se é uma forma de fugir da situação, porque é diferente aceitar e respeitar. Ou fazer de conta que não existe. "Não, eu não tenho preconceito. Desde que não fique perto de mim, não entre nas rodas onde eu estou”. Então eu percebo que essas questões são muito mais veladas entre os adultos, entre as gerações mais adultas, do que entre os próprios jovens. Entre eles, eles são bastante abertos a essas questões. (Grupo Focal, Professora Luna, 2018)

A professora Luna não aponta apenas o clima de medo em que vivem os/ as docentes; traz em sua fala a emergência de um discurso de reconhecimento das sexualidades, ainda que precário. Ao afirmar que os jovens "estão bastante abertos a essas questões", identifica que existe um reconhecimento em processo, algo que emerge como contestação e transformação do silêncio imposto pela violência ética em relação ao gênero e às sexualidades. Aqui poderíamos pensar em revoluções que ocorrem na educação (Torres Santomé, 2013), mas também dizem de permeabilidades como outras que se dão em diferentes domínios da vida. Os movimentos de LGBTI+ conseguem grande capilaridade social, seja em manifestações, como as paradas LGBTI+, seja ainda em redes da internet, produzindo semânticas de reconhecimento que, via estudantes e docentes, adentram na escola, como revelam as falas dos/as professores/as que colaboraram com nossas pesquisas. Destacamos que nos grupos focais não houve questões sobre travestilidade e transexualidade, indicando como o epistemicídio opera de forma mais violenta sobre esses corpos. Não abriremos essa discussão neste texto; ela está em elaboração em nosso grupo de pesquisa.

A entrevista narrativa da professora Luana, autoidentificada como mulher transexual, possibilitou localizarmos interdependências que se tornam fundamentais para o sujeito relatar a si para toda a comunidade escolar, produzir uma inteligibilidade capaz de enfrentar a violência ética que atinge as mulheres transexuais.

No contexto de nossas idas a campo, a entrevista narrativa foi importante para aprofundarmos nossas análises. A entrevista narrativa com Luana foi realizada pelo professor de curso profissionalizante, também autor deste artigo, em meados de 2017, com duração de pouco mais de 120 minutos. Também foram seguidos todos os procedimentos orientados pelo comitê de ética em pesquisa. $O$ pesquisador conheceu Luana durante sua atividade de professor no mesmo município em que ela atuava, numa cidade de médio porte a uns $80 \mathrm{~km}$ de Belo Horizonte. Após alguns encontros informais, Luana mostrou-se muito interessada em colaborar com a pesquisa, até mesmo mostrando um diário que tem produzido para registrar suas experiências. No período da pesquisa, ela estava com 25 anos aproximadamente, vivia com um companheiro e expressava uma performatividade de gênero feminina. Esse formato de entrevista narrativa parte de uma questão aberta com uma orientação ao narrador de falar o tempo que lhe aprouver. As entrevistas narrativas "se caracterizam como ferramentas não estruturadas, visando a profundidade, de 
aspectos não específicos, a partir das quais emergem histórias de vida, tanto do entrevistado como as entrecruzadas no contexto situacional" (Muylaert et al.,2014, p. 194). Também, acreditamos que a narrativa tem a legitimidade de um testemunho ao colocar alguém diante de uma audiência que está disposta a ouvir o relato dos/ das narradores/as (Hartmann, 2005).

Ao optar pela narrativa de uma mulher transexual, a professora Luana, desejávamos aprofundar o diálogo de nossa pesquisa com as especificidades da transfobia e/ou o reconhecimento das transexualidades. Em nossos grupos focais, o tema eram gênero e sexualidades, e nada apareceu acerca das travestilidades e transexualidades. Esse é um dado que informa como a sigla LGBTI+ ainda é insuficiente e/ou não se faz entender nos espaços escolares. O relato de professores/as sobre a insegurança em discutir as transgressões dos padrões hetero, principalmente tratando-se de identidades não binárias, como as pessoas trans, revela a capacidade da norma em moldar até a forma como as pessoas vão conhecer o gênero e as sexualidades e se referir a ambos. Desse modo, podemos entender como o regime de verdade por nós adjetivado como cisheteronormativo prejudica a semântica de reconhecimento nos processos de governabilidade dos corpos. Pois, ainda que a maioria dos/as colaboradores/as consiga nomear e denunciar a heteronormatividade, não se sente preparada para problematizar nem dialogar sobre padrões não dicotômicos de gênero, denunciando a não problematização e/ou o silenciamento acerca de travestis e transexuais nas escolas. O relato a seguir fala de como os sujeitos da escola se apropriam de determinadas questões acerca das transexualidades, algo que nos foi apresentado pela narrativa da professora Luana:

Essas nomenclaturas são um pouco complicadas. Mas é o meu ponto de vista. Porque definir exatamente até onde vai uma até onde vai a outra é muito complicado! E a cada ano vai aumentando. E o LGBT já virou LGBTTTT, não sei o quê... E, vai aumentando, porque é muito... vai abrangendo muita coisa... Porque vai falando, ela é isso, ela é aquilo... É difícil [definir]. Igual a Ivana [personagem transexual masculino da novela Força do Querer, da Rede Globo, exibida em 2017], com esse assunto tão em evidência, eu não assisto, quase não assisto televisão, mas leio muito, vejo as pessoas comentando, porque aí vira assunto da escola e está nessa evidência toda! A Ivana, pelo que eu entendi, porque as pessoas comentam, vira assunto da escola, vira assunto dos funcionários, dos alunos, pelo que eu entendi, não sei se corresponde, se você assiste, mas, assim, pelo que eu entendi a Ivana se identifica como homem, mas ela, sexualmente, ela gosta de homem. Não é de mulher! Que é assim, pra mim, pelo menos, até então e eu já li muita coisa, é diferente! Porque logo você espera que goste de mulher. Então é mais uma coisa, mais diferente ainda. Quando as meninas [colegas de trabalho] me contaram, na escola, porque até então eu não tinha lido sobre, só sobre a transformação, eu fiquei assim, nossa, é diferente... Porque pra isso um homem também vai ter que gostar; no caso dela, ela tem um namorado e tudo. $\mathrm{E}$ como que ele vai fazer? Porque, pra ele amar ela, ele vai ter que... Ela vai estar numa figura de homem, né? É difícil! É difícil! (Professora Luana, 2017) 
Compreendemos que, na narrativa de Luana, o reconhecimento de si se dá nas relações que contestam as normas do regime de verdade orientado pelas normas de gênero. A personagem Ivana, da novela, possibilitou a Luana estabelecer diálogos na escola acerca das possibilidades da experiência transexual: "Quando as meninas [colegas de trabalho] me contaram, na escola, porque até então eu não tinha lido sobre, só sobre a transformação...” (Professora Luana, 2017). Nesse diálogo existe uma aproximação entre Ivana e a professora Luana mediada pelas colegas de trabalho. Ivana é um homem trans que deseja outros homens. A experiência da professora Luana coloca em funcionamento mecanismos de subjetivação das possibilidades dos corpos definidos pelas transexualidades. O que faz as "meninas" interpelarem a professora com esse assunto? A aproximação entre "as meninas" e Luana diz de formas de reconhecimento, aponta para contestações e transformações diante de um regime de verdade que historicamente produziu corpos travestis e transexuais como abjeções, de maneira muito específica no contexto educacional. Aqui podemos reconhecer o surgimento de importantes relações marcadas pela solidariedade e empatia, condições necessárias para a construção de ambiências escolares mais democráticas e participativas (Torres Santomé, 2013).

Nesse ponto, podemos levar em conta como nos procedimentos de governo, no sentido proposto por Foucault (2018b), o indivíduo se constitui como sujeito na relação consigo e com os outros. De acordo com Júlio César Sanches (2010), a presença na mídia de corpos que rompem com a lógica binária sexual se faz muito significativa como modo de contestar a norma e reivindicar inteligibilidade e reconhecimento para esses corpos. A personagem Ivana ilustra o início desse processo, ao colocar em discurso corpos silenciados, pela interpelação da professora Luana. Esta, entre outros tantos adultos, jovens e adolescentes LGBTI+, constitui-se como "gente que veio para ficar" na escola. A voz desses sujeitos pode descolar posições LGBT fóbicas, trazer relatos de si. Talvez pela sua contestação das normas do regime de verdade, a escola como um espaço para todos/as consiga inventar novas formas de enfrentar a violência ética contra as sexualidades.

\section{CONSIDERAÇÕES FINAIS}

Nas falas ocorridas nos grupos focais e na entrevista narrativa de nossa pesquisa, analisamos como estão em curso disputas pela produção de uma verdade sobre a distribuição e destinação dos corpos, além da emergência de diferentes posições discursivas diante de um regime de verdade cisheteronormativo na escola, desde aquelas que se orientam por esse regime como outras que o contestam e/ou buscam formas de transformá-lo.

Nesse contexto, uma semântica produzida nas lutas sociais nos parece extremamente relevante para nomear e averiguar os modos como esse regime de verdade opera nas dinâmicas sociais. Podemos considerar que essas lutas sociais de mulheres LGBTI+, entre outros grupos submetidos a processos de des/classificação, ao afirmarem o reconhecimento de si na escola, tensionam o currículo oficial e indicam parte das revoluções de nossa época na educação (Torres Santomé, 2013). O termo LGBTfobia, compreendido como um dispositivo dinâmico nessas disputas, é um bom exemplo dessa semântica. Ainda que não tenhamos encontrado a ori- 
gem desse termo, percebemos pelas mídias sociais sua articulação por ativistas dos movimentos LGBTI+, principalmente por ocasião dos debates da criminalização da homofobia, o que é de domínio público. A noção de LGBTfobia ganha sentido político quando a tomamos como analisadora dos contextos escolares, apesar das questões teórico-metodológicas que podemos levantar acerca dela.

Foi desse modo que o termo homofobia se articulou a discursos de direitos humanos e nos movimentos sociais até ganhar sistematização acadêmica (Borrillo, 2010). Qual é a estratégia política em utilizar o termo LGBTfobia? O termo LGBTfobia parece emergir numa busca de organizar uma defesa mais alargada de LGBTI+ do que o termo homofobia. Por outro lado, essas siglas sempre portam ambiguidades, reduções que podem invisibilizar outros sujeitos. Todavia, afastar-se da produção de categorias êmicas que emergem no contexto das sexualidades, pensar num campo das sexualidades estritamente acadêmico, poderia nos tornar perpetradores/as da violência ética que analisamos, não dar lugar ao $e u$ que relata sobre si mesmo.

Tendemos a identificar na escola um discurso que nomeamos como reacionário raivoso pelos seus efeitos no contexto educacional, pois surge como uma forma cruel de reagir contra algo ou alguém haja vista certos anacronismos que não se tornam pretérito. A investida antigênero é uma articulação discursiva potente nas disputas que se desdobram entre os/as participantes da escola.

Tal investida também diz de uma ambiência internacional em que políticas neoliberais tomam a educação numa perspectiva economicista do capitalismo hegemônico. Aqui, temos o deslocamento das noções de tolerância, também problemáticas, para a explicitação da crueldade. No funcionamento da LGBTfobia temos a produção do medo, da violência, da constituição daqueles/as que podem ir para não mais voltar. A eliminação dos sujeitos e/ou de suas vozes se constitui como violência ética nas escolas, algo que pode ser rompido com o reconhecimento das sexualidades nesse contexto. Para esse reconhecimento, é preciso trazer a voz do $e u$ que relata a si.

Essa voz e as formas de reconhecimento que assistem a ela, produzindo cadeias semânticas em que sujeitos podem se vincular moralmente a formas de existência inteligíveis, são fundamentais para os direitos de LGBTI+. Nos contextos escolares, isso pode produzir análises que orientem para uma justiça curricular (Torres Santomé, 2013) mais atenta às urgências de enfrentamento da LGBT fobia. Um jovem estudante que é ameaçado pelo enunciado "Bolsonaro vai matar todos os viados" precisa ter possibilidades de se defender e de ser defendido por outros no contexto escolar. $\mathrm{O}$ "corpo viado" é um modo de expressão e produção de saberes acerca do mundo, e o desejo de destruí-lo faz parte da tentativa de se subtrair da escola formas de saberes, o que entendemos como parte do epistemicídio (Carneiro, 2005) das sexualidades. O desejo de eliminação do outro, aqui identificado como viado, figura como uma tentativa de eliminar a inteligibilidade de um corpo que denuncia os anacronismos morais, estes incapazes de dialogar com performatividades que já não cabem nos estreitos limites das máximas morais de nossa sociedade, como analisa Butlter (2015).

$\mathrm{Na}$ perspectiva de Butler (2015), o relato de si inaugura uma reflexividade em que o eu está em conformidade com a normalização ética e com os referenciais morais de uma matriz prevalecente. A autora articula sua análise com base em Foucault (2018a; 2018b) acerca da constituição dos modos de ser do sujeito nos 
procedimentos do governo de si e dos outros em determinados regimes de verdade. Nossas análises apontaram tanto para a produção do contexto de vidas insuportáveis como para a constituição de resistências que buscam pela possibilidade de vidas habitáveis. Estas são vidas que sustentam o desejo de reconhecimento, porém num cenário marcado pelo recrudescimento de posições LGBTfóbicas.

Nem os relatos dos grupos focais nem a narrativa da professora Luana podem ser considerados um relato de si, mas os/as docentes trazem no que disseram indícios e ruídos da constituição de condições para que esse relato se articule. Os modos como docentes e demais membros da comunidade escolar lidam com as contestações da norma de gênero na escola podem produzir ambiências im/possíveis para o reconhecimento das sexualidades.

Consideramos que a escola, como território de interdependências humanas extremamente complexas, é irredutível a análises absolutas, pois os relatos que dela emanam em nossas pesquisas indicam possibilidades a LGBTI+. Na escola também se têm articulado outros discursos de reconhecimento das sexualidades. Isso ocorre até mesmo pelos corpos que rompem com as performatividades reguladas pela norma de gênero e habitam em seu cotidiano. Determinadas articulações discursivas - ainda que pontuais — realizadas por alguns educadores/as nos indicam formas de resistência a processos de eliminação e subalternização de participantes da comunidade escolar, pois a inteligibilidade de muitos dos/as colaboradores/as desta pesquisa em nomear e denunciar a cisheteronormatividade revelam certa resistência à ofensiva antigênero. Constituem como possibilidades de problematizar para a comunidade escolar as normas reguladoras do gênero e das sexualidades, que precisam ser desnaturalizadas, contestadas, transformadas.

O relato da professora Luana e dos/as educadores/as provocados/as a reconhecer outras performatividades de gênero pode sugerir um modo como docentes reconhecem ou não as sexualidades, que LGBTI+ podem ser considerados/as "gente que chegou para ficar" na escola, pessoas que pela sua voz podem romper com a violência ética que silencia as dores e os sofrimentos de muitos/as no cotidiano escolar.

\section{REFERÊNCIAS}

BAGGIO, K. G. Conexões ultraliberais nas Américas: o think-tank norte-americano Atlas Network e suas vinculações com organizações latino-americanas. In: ENCONTRO INTERNACIONAL DA ANPHLAC, 12., 2016. Anais... 2016.

BARBOUR, R. Grupos Focais. Porto Alegre: Artmed, 2009.

BONDÍA, J. L. Tremores: escritos sobre experiência. Trad. Cristina Antunes e João Wanderley Geraldi. Belo Horizonte: Autêntica, 2015.

BORRILLO, D. Homofobia: história e crítica de um preconceito. Trad. Guilherme J. de Freitas Teixeira. Belo Horizonte: Autêntica, 2010.

BRAH, A. Diferença, diversidade, diferenciação. Cadernos Pagu, Campinas, n. 26, p. 329-376, jun. 2006. Disponível em: http://www.scielo.br/scielo.php?script=sci arttext\&pid=S0104-83332006000100014\&lng=en\&nrm=iso. Acesso em: 20 fev. 2016. https://doi.org/10.1590/S0104-83332006000100014 
BRASIL. Plano Nacional de Promoção da Cidadania e dos Direitos Humanos de LGBT (PNLGBT). Brasília: Secretaria Especial de Direitos Humanos, 2009. Disponível em: https://www2.mppa.mp.br/sistemas/gcsubsites/upload/39/LGBTI/ Plano\%20Nacional\%20de\%20Promo\%C3\%A7\%C3\%A3o\%20da\%20Cidadania\%20 e\%20Direitos\%20Humanos\%20LGBTI.pdf. Acesso em: 10 fev. 2019.

BRASIL. Ministério do Planejamento, Orçamento e Gestão. Análise dos resultados. In: BRASIL. Indicadores sociais municipais: uma análise dos resultados do universo do Censo Demográfico 2010. Rio de Janeiro: Ministério do Planejamento, Orçamento e Gestão, 2011. p. 27-81. Disponível em: https://biblioteca.ibge.gov.br/visualizacao/ livros/liv54598.pdf. Acesso em: 4 jul. 2019.

BUTLER,J.Problemas de Gênero: feminismo e subversão da identidade. Trad. Renato Aguiar. Rio de Janeiro: Civilização Brasileira, 2003.

BUTLER, J. Relatar a si mesmo: Crítica da violência ética. Trad. Rogério Bettoni. Belo Horizonte: Autêntica, 2015.

CARNEIRO, S. A construção do outro como não-ser como fundamento do ser. 339 f. 2005. Tese (Doutorado em Educação) - Universidade de São Paulo, São Paulo, 2005. COSTA, Â. B.; NARDI, H. C. Homofobia e preconceito contra diversidade sexual: debate conceitual. Temas em Psicologia, Ribeirão Preto, v. 23, n. 3, p. 715-726, set. 2015. Disponível em: http://pepsic.bvsalud.org/scielo.php?script=sci_arttext\&pid=S1413389X2015000300015\&lng=pt\&nrm=iso. Acesso em: 9 abr. 2019. http://dx.doi. org/10.9788/TP2015.3-15

FISCHER, R. M. B. Foucault e a análise do discurso em educação. Cadernos de Pesquisa, São Paulo, n. 114, p. 197-223, nov. 2001. Disponível em: http://www.scielo. br/scielo.php?script=sci_arttext\&pid=S0100-15742001000300009\&lng=en\&nrm=i so. Acesso em: 22 maio 2019. https://doi.org/10.1590/S0100-15742001000300009

FOUCAULT, M. Vigiar e punir: nascimento da prisão. Trad. Raquel Ramalhete. Petrópolis: Vozes, 1987.

FOUCAULT, M. História da sexualidade I: a vontade de saber. Trad. Maria T. da C. Albuquerque e J. A. G. Albuquerque. 15. ed. Rio de Janeiro: Graal, 1988.

FOUCAULT, M. Do governo dos vivos: Curso no Collège de France (1979-1980). Trad. Eduardo Brandão. São Paulo: WMFMartins Fontes, 2018a.

FOUCAULT, M. O governo de si e dos outros. Curso no Collège de France (19821983). Trad. Eduardo Brandão. São Paulo: WMFMartins Fontes, 2018b.

GATTI, B. A. Grupo focal na pesquisa em ciências sociais e humanas. Brasília: Líder Livro, 2005.

GRUPO FOCAL. Grupo focal: entrevista [maio,jun. e out. 2018]. Mediadora: Izabella Marina Martinho Saraiva. Mariana, 2017. 1 arquivo mp3.

HARTMANN, L. Performance e experiência nas narrativas orais da fronteira entre Argentina, Brasil e Uruguai. Horizontes Antropológicos, Porto Alegre, v. 11, n. 24, p. 125-153, dez. 2005. Disponível em: https://doi.org/10.1590/S010471832005000200007. Acesso em: 28 abr. 2017. 
JUNQUEIRA, R. D. Homofobia: limites e possibilidades de um conceito em meio a disputas. Bagoas, v. 1, n. 1, p. 1-24, jul./dez. 2007. Disponível em: http://www.cchla. ufrn.br/bagoas/v01n01art07_junqueira.pdf. Acesso em: 10 fev. 2019.

JUNQUEIRA, R. D. A invenção da “ideologia de gênero”: a emergência de um cenário político-discursivo e a elaboração de uma retórica reacionária antigênero. Revista Psicologia Política, São Paulo, v. 18, n. 43, p. 449-502, dez.2018. Disponível em: http:// pepsic.bvsalud.org/scielo.php?script=sci_arttext\&pid=S1519-549X2018000300004\&1 ng=pt\&nrm=iso. Acesso em: 28 abr. 2019.

MATTOS, A. R. Discursos ultraconservadores e o truque da “ideologia de gênero": gênero e sexualidades em disputa na educação. Revista Psicologia Política, São Paulo, v. 18, n. 43, p. 573-586, dez.2018. Disponível em: http://pepsic.bvsalud.org/scielo.php?script=sci_ arttext\&pid=S1519-549X2018000300009\&lng=pt\&nrm=iso. Acesso em:30 maio 2019. MATTOS, A. R.; CIDADE, M.L. R. Para pensar a cisheteronormatividade na psicologia: lições tomadas do transfeminismo. Periódicus, Salvador, v. 1, n. 5, p. 132-153, maio-out. 2016. Disponível em: https://portalseer.ufba.br/index.php/revistaperiodicus/article/ viewFile/17181/11338. Acesso em: 20 fev.2018. http://dx.doi.org/10.9771/peri.v1i5.17181 MOUTINHO, L. Diferenças e desigualdades negociadas: raça, sexualidade e gênero em produções acadêmicas recentes.CadenosPagu,Campinas,n.42,p.201-248,jun.2014.Disponível em:http:/www.scielo.br/scielo.php?script=sci_arttext\&pid=S0104-83332014000100201\&ln $\mathrm{g}=$ en\&nrm=iso. Acesso em: 5 set. 2020. https://doi.org/10.1590/0104-8333201400420201 MUYLAERT, C. J. et al. Entrevistas narrativas: um importante recurso em pesquisa qualitativa. Revista da Escola de Enfermagem da USP, São Paulo, v. 48, n. esp. 2, p. 184-189, dez. 2014. Disponível em: http://www.scielo.br/scielo.php?script=sci_ arttext\&pid=S0080-62342014000800184\&lng=en\&nrm=iso. Acesso em: 11 jan. 2019. https://doi.org/10.1590/S0080-623420140000800027

NASCIMENTO,M.;BRANT,F.Encontrose Despedidas. Brasil: Selo Barclay/Ariola, 1985.

OLIVEIRA, D. A.; FERRARI, A. Interseccionalidade, gênero, sexualidade e raça: os desafios e as potencialidades na invenção de outros currículos. Diversidade e Educação, v. 6, n. 1, p. 21-29, 2018. Disponível em: https://periodicos.furg.br/divedu/article/ view/8234. Acesso em: 28 abr. 2019. https://doi.org/10.14295/de.v6i1.8234

OLIVEIRA, D. A.; FERRARI, A.; MACHADO, N. N. "Ninguém solta a mão de ninguém": conectados/as em rede, resistimos. Práxis Educativa, Ponta Grossa, v. 14, n. 2, p. 659-677, maio/ago. 2019. Disponível em: https://doi.org/10.5212/ PraxEduc.v.14n2.014. Acesso em: 28 maio 2019.

PRADO, M. A. M.; CORREA, S. Retratos transnacionais e nacionais das cruzadas antigênero. Revista Psicologia Política, São Paulo, v. 18, n. 43, p. 444-448, dez. 2018. Disponível em: http://pepsic.bvsalud.org/scielo.php?script=sci_arttext\&pid=S1519549X2018000300003\&lng=pt\&nrm=iso. Acesso em: 30 maio 2019.

PROFESSORA Luana. Professora Luana: entrevista narrativa [ago. 2017]. Entrevistador: Rubens Modesto Gonzaga. Congonhas, 2017. 1 arquivo mp3.

REIS, T. (Org.). Manual de Comunicação LGBTI+. Curitiba: Aliança Nacional LGBTI / GayLatino, 2018. Disponível em: https://www.grupodignidade.org.br/wpcontent/uploads/2018/05/manual-comunicacao-LGBTI.pdf. Acesso em:5 mar. 2019. 
REIS,T:; EGGERT,E. Ideologia de gênero: uma falácia construída sobre os planos de educação brasileiros. Educação e Sociedade, Campinas, v. 38, n. 138, p. 9-26, jan. 2017. Disponível em: http://www.scielo.br/scielo.php?script=sci_arttext\&pid=S0101-73302017000100009\&lng= en\&nrm=iso. Acesso em: 13 jun. 2018. http://dx.doi.org/10.1590/es0101-73302017165522 SAFLATE, V.Dos problemas de gênero a uma teoria da despossessão necessária: ética, política e reconhecimento em Judith Butler. In: BUTLER, J. Relatar a si mesmo: Crítica da violência ética. Trad. Rogério Bettoni. Belo Horizonte: Autêntica, 2015. p.173-196. SANCHES, J. C. Corpos performativos: Os entre-lugares e as zonas Queers em Lady Gaga. Redescrições, Curitiba, v. 2, n. 3, p. 7-17, 2010. Disponível em: https://revistas. ufrj.br/index.php/Redescricoes/article/view/15106. Acesso em: 6 mar. 2018.

SMEHA, L. N. Aspectos epistemológicos subjacentes a escolha da técnica do grupo focal da pesquisa qualitativa. Revista de Psicologia da IMED, Passo Fundo, v. 1, n. 2, p. 260-268, 2009. Disponível em: https://seer.imed.edu.br/index.php/revistapsico/ article/view/35/34. Acesso em: 20 jun. 2018.

TEIXEIRA-FILHO, F. S.; RONDINI, C. A. Ideações e tentativas de suicídio em adolescentes com práticas sexuais hetero e homoeróticas. Saúde e Sociedade, v. 21, n. 3, p. 651-667, 2012. Disponível em: https://www.scielo.br/scielo.php?pid=S010412902012000300011\&script=sci_abstract\&tlng=pt. Acesso em: 10 fev. 2019. http:// dx.doi.org/10.1590/S0104-12902012000300011

TORRES SANTOMÉ, J. Currículo escolar e justiça social: o cavalo de Troia da educação. Trad. Alexandre Salvaterra. Porto Alegre: Penso, 2013.

VIANNA, C. Políticas de educação, gênero e diversidade sexual: breve história de lutas, danos e resistências. Belo Horizonte: Autêntica, 2018.

\section{SOBRE OS AUTORES}

Marco Antônio Torres é doutor em psicologia pela Universidade Federal de Minas Gerais (UFMG). Professor da Universidade Federal de Ouro Preto (UFOP). E-mail: torresgerais@gmail.com

Izabella Marina Martinho Saraiva é mestranda em educação pela Universidade Federal de Ouro Preto (UFOP).

E-mail: bebelamartinho@hotmail.com

Rubens Modesto GonZaga é mestre em educação pela Universidade Federal de Ouro Preto (UFOP). Assistente em Administração na mesma instituição. E-mail: rubensmodesto2006@yahoo.com.br

Recebido em $1^{\circ}$ de agosto de 2019

Aprovado em 7 de maio de 2020 